\title{
Influence of surface defects on the fatigue crack initiation in pearlitic steel
}

\author{
Jesús Toribio ${ }^{1, a}$, Juan Carlos Matos² and Beatriz González ${ }^{1}$ \\ ${ }^{1}$ Materials Engineering, University of Salamanca, E.P.S., Avda. Requejo, 33, 49022 Zamora, Spain \\ ${ }^{2}$ Computing Engineering, University of Salamanca, E.P.S., Avda. Requejo, 33, 49022 Zamora, Spain
}

\begin{abstract}
Tensile fatigue tests were performed under load control, with constant stress range $\Delta \sigma$ on pearlitic steel wires, from the hot rolled bar to the commercial prestressing steel wire (which has undergone seven cold drawing steps). Results show that fatigue cracks in pearlitic steels initiate at the wire surface starting from small defects, whose size decreases with the drawing process. Fatigue cracks created from defects (initiation phase) exhibit a fractographic appearance consisting of ductile microtearing events which can be classified as tearing topography surface or TTS, and exhibit a remarkably lower spacing in the prestressing steel wire than in the hot rolled bar. In addition, some $S-N$ tests were performed in both material forms under a stress range of about half the yield strength. In these tests, the main part of the fatigue life corresponds to the propagation stage in the hot rolled bar whereas such a main part of the life is associated with the initiation stage in the case of the prestressing steel wire.
\end{abstract}

\section{Introduction}

This paper studies the defects able to initiate the fatigue phenomenon in pearlitic steel before and after cold drawing by analyzing the effects of the strain hardening procedure on such defects and on the microstructural arrangement and how these material features affect the fatigue performance of the steel.

\section{Experimental results and discussion}

The material used was eutectoid pearlitic steel. It was studied in two phases: firstly, as a hot rolled bar (non cold drawn at all) and, secondly, as a commercial prestressing steel wire which has undergone seven cold drawing steps and a posterior stress-relieving treatment. Cold drawing produces important microstructural changes in the pearlitic steel in the form of slenderizing of pearlitic colonies, decrease of interlamellar spacing of pearlite and progressive orientation with cold drawing of both colonies and lamellae.

\footnotetext{
${ }^{a}$ Corresponding author: toribio@usal.es
}

This is an Open Access article distributed under the terms of the Creative Commons Attribution License 4.0, which permits unrestricted use, distribution, and reproduction in any medium, provided the original work is properly cited. 


\section{MATEC Web of Conferences}
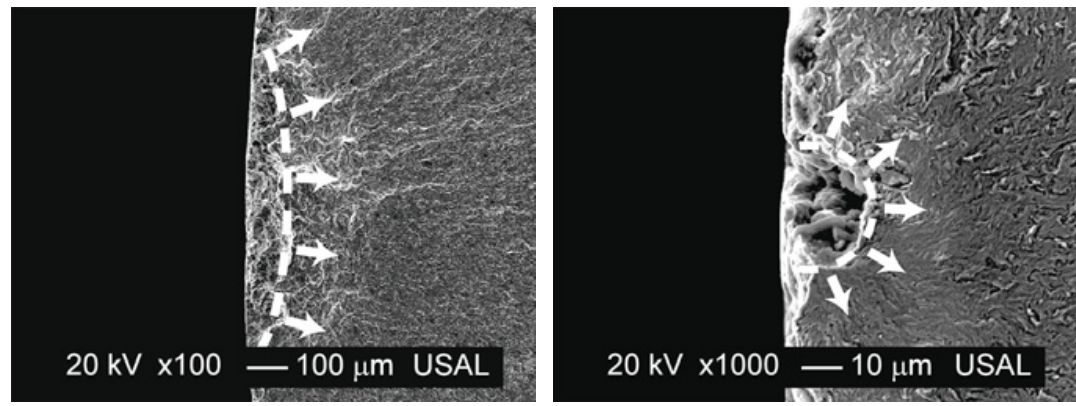

Figure 1. Initiation of fatigue crack growth from a surface defect: hot rolled bar (left) and prestressing steel wire (right), including arrows to identify the fatigue crack growth from defect.

Wöhler fatigue tests were performed under tensile load control with constant $\Delta \sigma$, sinusoidal wave shape, frequency of $10 \mathrm{~Hz}, R$-ratio $R=0$ and a maximum stress lower than the yield stress $\sigma_{\mathrm{Y}}$ (some $S$ - $N$ tests were performed under a stress range of about half the yield strength).

Results show that fatigue cracks in pearlitic steels begin at the wire surface starting from small defects (Fig. 1). In the hot rolled bar the fatigue initiators are mainly the surface defects with small aspect ratio (material losses at the peripheral zones) while in the prestressing steel wire such initiators are principally the voids created by, probably, the existence of particles near the wire surface [1]. Many times surface defects are caused by the drawing process itself [2]. The defect size decreases with the drawing process.

Fatigue cracks created from defects exhibit a fractographic appearance consisting of ductile microtearing events, which can be classified as tearing topography surface or TTS [3]. Such microtearings exhibit a spacing remarkably lower in the prestressing steel wire than in the hot rolled bar, so that their size decreases with cold drawing as the steel microstructure does, and a sort of materials science relationship appears between microstructural unit size and fatigue microfracture event.

In the Whöler tests, smooth specimens (samples of the as-supplied wire) were subjected to fatigue loading under constant amplitude, stress level of about half of the yield strength, up to fracture. The main part of the fatigue life (measured as number of cycles) is associated with the propagation phase in the hot rolled bar and with the initiation phase in the cold drawn wire (where the common definition of initiation in reality pertains to both nucleation and propagation of microcracks).

The cold drawing is beneficial since it improves both the fatigue and the fracture performance by dropping the Paris law and elevating the fracture toughness, a clear implication for structural engineers. Moreover, the prestressing steel wire is again the best option on the basis of a clear reduction of the size of the surface defects (acting as crack initiators) and the microstructural changes induced by the drawing process. Both characteristics contribute to a delay of the initiation of fatigue crack growth.

\section{Conclusions}

(i) In the hot rolled bar the fatigue initiators are mainly the surface defects (material losses) while in the prestressing steel wire such initiators are principally the voids created by the existence of particles near the wire surface. The defect size decreases with the drawing process.

(ii) Fatigue cracks created from defects exhibit a fractographic appearance consisting of ductile microtearing events which can be classified as tearing topography surface or TTS, and exhibit a spacing remarkably lower in the prestressing steel wire than in the hot rolled bar. 
(iii) The number of cycles necessary for fatigue crack initiation in the prestressing steel wire is quite higher than that of the hot rolled bar (for $\Delta \sigma=\sigma_{\mathrm{Y}} / 2$ ) and thus changes in surface defects and microstructural arrangement produced by the drawing process improves the fatigue performance.

\section{References}

[1] I. Verpoest, E. Aernoudt, A. Deruyttere, M. de Bondt. Int. J. Fatigue 7, 199-214 (1985)

[2] S. Beretta, S. Matteazzi. Int. J. Fatigue 18, 451-456 (1996)

[3] A.W. Thompson, J.C. Chesnutt. Metall. Trans. 10A, 1193-1196 (1979) 